\title{
Optimasi Konsentrasi Larutan Hara Pada Budidaya Selada (Lactuca sativa L. cv. Grand Rapid) dengan Teknologi Hidroponik Sistem Terapung
}

\author{
Optimizing of Nutrient Solution Concentration for Lettuce (Lactuca sativa L. cv. Grand Rapid) \\ in Deep Pool Growing System
}

\author{
Erni Ratna Wulan ${ }^{1}$, Anas D. Susila ${ }^{2,3^{*}}$ \\ ${ }^{1}$ Program Studi Agronomi dan Hortikultura, Departeman Agronomi dan Hortikultura, \\ Fakultas Pertanian, Institut Pertanian Bogor \\ ${ }^{2}$ Departeman Agronomi dan Hortikultura, Fakultas Pertanian, Institut Pertanian Bogor \\ Jl. Meranti, Kampus IPB Darmaga Bogor, Telp/Fax: 0251-629353 \\ ${ }^{3}$ Pusat Kajian Hortikultura Tropika, Lembaga Penelitian dan Pengabdian pada Masyarakat Institut Pertanian Bogor, \\ Jl. Raya Pajajaran, Kampus IPB Baranangsiang, Bogor, Indonesia \\ Diterima 14 Mei 2018/Disetujui 11 Juni 2018
}

\begin{abstract}
The objective of this research was determined the optimum nutrient solution concentration on lettuce growth and yield in Deep Pool Growing System (THST). The study was conducted from November 2005 to March 2006 at Deep Pool Growing System facilities, Danasworo Hydrogarden Ciapus, Bogor (S 6038'.19.78”, E 106 45'44.52'). The study was arranged in Completely Randomized Design with four levels of nutrient solution concentration. These are control (without nutrient), EC $0.75 \mathrm{mS} . \mathrm{cm}^{-1}, E C 1.50 \mathrm{mS} . \mathrm{cm}^{-1}$ and EC $2.25 \mathrm{mS} . \mathrm{cm}^{-1}$. The composition of AB Mix nutrient solution were as followed (ppm): $\mathrm{NH}_{4}^{+} 22.5, \mathrm{~K}^{+} 429, \mathrm{Ca}^{2+} 180, \mathrm{Mg}^{2+} 24, \mathrm{NO}_{3}^{-} 1178, \mathrm{SO}_{4}^{2-} 108, \mathrm{H}_{2} \mathrm{PO}_{4}^{-}$194, $\mathrm{Fe}^{3+} 2.232, \mathrm{Mn}^{3+} 0.275, \mathrm{Zn}^{2+} 0.261, \mathrm{~B}^{3+} 0.324, \mathrm{Cu}^{2+}$ 0.049 dan $\mathrm{Mo}^{2+}$ 0.048. Lettuce growth and yield was quadratically increased with nutrient solution concentrations application from 0 to $2.25 \mathrm{mS} . \mathrm{cm}^{-1}$. Base on total plant weight and marketable plant weight, recommendation range of optimum nutrient solution concentration for lettuce hydroponic production in THST was between 1.09-1.15 $\mathrm{mS}_{\mathrm{cm}} \mathrm{cm}^{-1}$.
\end{abstract}

Keyword : deep pool growing system, hydroponic, lettuce, nutrient solution

ABSTRAK

Tujuan dari penelitian ini adalah untuk menetapkan konsentrasi larutan hara optimum pada pertumbuhan dan hasil selada dalam budidaya Teknik Hidroponik Sistem Terapung (THST). Penelitian dilakukan mulai November 2005 hingga Maret 2006 di THST Danasworo Hydrogarden Ciapus, Bogor (S 6038'.19.78 ', E 106 45'44.52”). Penelitian ini disusun dalam rancangan acak lengkap dengan empat tingkat konsentrasi larutan hara yaitu kontrol (EC $\left.0 \mathrm{mS} . \mathrm{cm}^{-1}\right), E C 0.75 \mathrm{mS} . \mathrm{cm}^{-1}$, EC $1.50 \mathrm{mS} . \mathrm{cm}^{-1}$ dan EC $2.25 \mathrm{mS} . \mathrm{cm}^{-1}$. Komposisi larutan nutrisi AB Mix adalah sebagai berikut (ppm): $\mathrm{NH}_{4}^{+} 22.5, \mathrm{~K}^{+} 429$, $\mathrm{Ca}^{2+}$ 180, $\mathrm{Mg}^{2+}$ 24, $\mathrm{NO}_{3}^{-}$1178, $\mathrm{SO}_{4}^{2-}$ 108, $\mathrm{H}_{2} \mathrm{PO}_{4}^{-}$194, $\mathrm{Fe}^{3+}$ 2.232, $\mathrm{Mn}^{3+}$ 0.275, $\mathrm{Zn}^{2+}$ 0.261, $\mathrm{B}^{3+} 0.324, \mathrm{Cu}^{2+} 0.049 \mathrm{dan} \mathrm{Mo}^{2+}$ 0.048. Pertumbuhan dan hasil hasil secara kuadratik meningkat dengan aplikasi konsentrasi larutan hara dari 0 hingga 2,25 mS.cm ${ }^{-1}$. Berdasarkan total bobot tanaman dan berat tanaman yang dapat dipasarkan, kisaran rekomendasi konsentrasi larutan hara optimum untuk produksi hidroponik selada dalam THST adalah antara 1.09-1.15 mS.cm ${ }^{-1}$.

Kata kunci : hidroponik, larutan nutrisi, selada, teknik hidroponik sistem terapung (THST)

\section{PENDAHULUAN}

Komoditas sayuran merupakan kelompok tanaman hortikultura di sub sektor pertanian yang cukup berperan dalam pemenuhan gizi masyarakat dan memberikan kontribusi pada peningkatan pendapatan masyarakat. Selada dikenal kontribusi gizinya sebagai sumber mineral, pro

\footnotetext{
* Penulis untuk korespondensi. e-mail: anasdsusila@ipb.ac.id
}

vitamin A, vitamin C dan serat (Rubatzky dan Yamaguchi, 1998). Meningkatnya taraf hidup masyarakat menuntut juga tersedianya bahan pangan yang berkualitas dan aman untuk dikonsumsi, sehingga dibutuhkan suatu sistem budidaya tanaman yang dapat menghasilkan tanaman yang yang berkualitas dan sehat. Salah satunya sistem budidaya tersebut adalah adalah sistem hidroponik. Budidaya tanaman secara hidroponik merupakan teknologi maju dalam bidang pertanian khususnya tanaman hortikultura yang dapat menghasilkan produktivitas dan kualitas sesuai dengan perencanaan. Hidroponik merupakan salah satu cara 
budidaya tanaman yang menggunakan prinsip penyediaan larutan hara yang tepat sesuai dengan kebutuhan tanaman. Teknologi Hidroponik Sistem Terapung (THST) merupakan pengembangan aplikasi teknologi hidroponik sederhana yang sedikit memerlukan penggunaan energi listrik. Kendala utama dalam THST adalah terendamnya akar tanaman dalam larutan hara sehingga ketersediaan oksigen di sekitar rhizosfer berkurang. Kondisi seperti ini akan menyebabkan pertumbuhan tanaman yang terhambat, kelayuan, dan bahkan kematian. Namun demikian, hal tersebut dapat diatasi dengan penggunaan media tanam rockwool sebagai bahan pemegang tanaman (Susila dan Koerniawati, 2003).

Penggunaan konsentrasi larutan hara merupakan salah satu faktor yang harus diperhatikan dalam budidaya hidroponik. Setiap jenis tanaman memerlukan tingkatan konsentrasi hara yang berbeda. Tingkatan konsentrasi larutan hara yang di diukur sebagai EC (Electrical Canductivity) dalam kondisi rendah ataupun terlalu tinggi dapat menghambat pertumbuhan tanaman (Roan, 1998). Berdasarkan hasil penelitian Nurfinayanti (2004) selada tumbuh baik pada kisaran EC $300-1550 \mu \mathrm{S} . \mathrm{cm}^{-1}$. Namun demikian, belum tersedia rekomendasi konsentrasi larutan hara yang optimum untuk budidaya selada dalam sistem THST. Penelitian ini bertujan untuk menetapkan konsentrasi larutan hara yang optimum terhadap pertumbuhan dan produksi selada yang dibudidayakan dalam sistem THST.

\section{BAHAN DAN METODE}

Penelitian ini dilaksanakan mulai November 2005 hingga Maret 2006, bertempat di fasilitas Deep Pool Growing System, Danasworo Hydrogarden, Ciapus Bogor (S 6038'.19.78”, E 106 45'44.52'). Lokasi ini berada pada ketinggian $411 \mathrm{~m}$ dpl dengan suhu greenhouse harian 22 $36^{\circ} \mathrm{C}$.

Penelitian disusun dalam Rancangan Acak Lengkap (RAL) dengan faktor tunggal yaitu konsentrasi larutan hara yang terdiri dari 4 taraf perlakuan. Konsentrasi larutan hara diukur berdasarkan nilai konduktivitas atau EC (Electrical Conductivity) dalam satuan $\mathrm{mS} \cdot \mathrm{cm}^{-1}$. Empat taraf perlakuan tersebut yaitu K1 (kontrol/tanpa penambahan hara), K2 $\left(\mathrm{EC}=0.75 \mathrm{mS} . \mathrm{cm}^{-1}\right), \quad \mathrm{K} 3 \quad\left(\mathrm{EC}=1.50 \mathrm{mS} . \mathrm{cm}^{-1}\right)$ dan $\mathrm{K} 4$ $\left(\mathrm{EC}=2.25 \mathrm{mS} . \mathrm{cm}^{-1}\right)$. Masing-masing perlakuan terdiri dari 20 ulangan sehingga terdapat 80 unit percobaan dengan 15 tanaman untuk setiap unit percobaan.

Varietas Selada Grand Rapid disemaikan menggunakan media tanam rockwool dalam panel semai 77 (untuk pembesaran bibit), setelah umur 4 minggu setelah semai bibit dipindah tanamkan ke panel 15 (panel tanam) dan diapungkan di atas larutan hara. Panel 15 dan panen 77 berbahan styrofoam memiliki ketebalan $4 \mathrm{~cm}$ dan ukuran 60 cm panjang x $40 \mathrm{~cm}$ lebar. Panel tanam (floating) diletakkan pada kolam yang terbuat dari cor beton dengan panjang 17 m lebar $3 \mathrm{~m}$ dan tinggi $0.6 \mathrm{~m}$. Kolam ini berada di dalam greenhouse dengan dinding paranet $55 \%$, dan beratap UV plastik (12\%) dengan ketebalan $0.02 \mathrm{~mm}$. Larutan hara menggunakan $\mathrm{AB}$ mix yang terdiri dari larutan stock $\mathrm{A}$ dan larutan stock B. Komposisi larutan hara stok A terdiri dari
$\mathrm{KNO}_{3}, \mathrm{Ca}\left(\mathrm{NO}_{3}\right)_{2}$, Fe-EDTA sedangkan komposisi larutan stok B terdiri dari $\mathrm{KNO}_{3}, \mathrm{KH}_{2} \mathrm{PO}_{4}, \mathrm{MgSO}_{4}, \mathrm{MnSO}_{4}, \mathrm{CuSO}_{4}$, $\left(\mathrm{NH}_{4}\right)_{2} \mathrm{SO}_{4}, \mathrm{Na}_{2} \mathrm{HBO}_{3}, \mathrm{ZnSO}_{4}$ dan $\mathrm{Na}_{2} \mathrm{MoO}_{4}$. Komposisi ion-ion hara yang terdapat di dalam larutan hara $\mathrm{AB}$ Mix yaitu $\mathrm{NH}_{4}^{+} 22.5 \mathrm{ppm}, \mathrm{K}^{+} 429 \mathrm{ppm}, \mathrm{Ca}^{2+} 180 \mathrm{ppm}, \mathrm{Mg}^{2+} 24$ ppm, $\mathrm{NO}_{3}^{-} 1178$ ppm, $\mathrm{SO}_{4}^{2-} 108 \mathrm{ppm}, \mathrm{H}_{2} \mathrm{PO}_{4}^{-} 194 \mathrm{ppm}, \mathrm{Fe}^{3+}$ $2.232 \mathrm{ppm}, \mathrm{Mn}^{3+} 0.275 \mathrm{ppm}, \mathrm{Zn}^{2+} 0.261 \mathrm{ppm}, \mathrm{B}^{3+}$ 0.324, $\mathrm{Cu}^{2+} 0.049 \mathrm{ppm}$ dan $\mathrm{Mo}^{2+} 0.048 \mathrm{ppm}$. Selain itu, pupuk daun Gandasil D (12-14-12) digunakan dalam pemeliharaan tanaman. Pengukuraan $\mathrm{pH}$ dan konsentrasi larutan hara dilakukan menggunakan $\mathrm{pH}$ dan $\mathrm{EC}$ meter digital HANNA Type HI 991300, Dissolved Oxygen (DO) diukur menggunakan DO meter digital YSI 550A, kelembaan dan suhu udara dalam greenhouse diukur menggunakan termohigrometer Extech 445703, sementara intensitas cahaya diukur menggunakan lightmeter HandyMAN TEK1336, dan bobot tanaman ditimbang menggunakan timbangan digital Henherr ACS-H1 LED.

Persiapan percobaan meliputi pembersihan greenhouse dan pengisian larutan hara pada kolam sesuai perlakuan dengan ketinggian larutan sekitar $20 \mathrm{~cm}$ dan persiapan tray untuk persemaian. Benih disemai pada tray plastik dengan kertas tisu yang telah dibasahi. Penyemaian ini dilakukan selama 3 hari dan diletakkan di ruang yang gelap. Benih yang tumbuh ditransplanting pada panel 77 dengan media rockwool dan dipelihara selama 4 minggu. Pemeliharaan tanaman di persemaian meliputi penyiraman dan pemberian pupuk daun Gandasil dengan dosis $2 \mathrm{~g} \mathrm{~L}^{-1}$ setiap 2 hari sekali. Tanaman yang telah ditransplanting kemudian ditanam pada panel 15, lalu diapungkan (floating) di atas kolam sesuai dengan perlakuan selama 4 minggu. Setelah 4 minggu floating, dilakukan pemanenan dengan cara mencabut seluruh tanaman beserta rockwoolnya.

Pengamatan harian, meliputi suhu dan kelembaban greenhouse, EC, pH, DO (Dissolved Oxygen) dan suhu larutan. Pengamatan ini dilakukan pada pagi (pukul 08.00), siang (pukul 12.00) dan sore hari (pukul 16.00). Pengamatan mingguan, meliputi pengamatan intensitas cahaya luar dan dalam greenhouse, tinggi tanaman, jumlah daun dan diameter batang. Pengamatan saat panen, meliputi : jumlah tanaman hidup per panel, bobot total per panel, bobot yang dapat dipasarkan (marketable) per panel, bobot total per tanaman, bobot akar per tanaman, bobot marketable per tanaman dan panjang akar. Sebelum pemanenan dilakukan analisis klorofil dan analisis N, P dan K jaringan tanaman. Data yang diperoleh diuji dengan uji F. Jika menunjukkan pengaruh yang nyata maka pengujian dilanjutkan dengan uji Regresi polinomial.

\section{HASIL DAN PEMBAHASAN}

\section{Kondisi Umum}

Pertumbuhan tanaman selada hingga akhir penelitian cukup baik. Selama penelitian berlangsung, ditemukan tiga ulat grayak (Spodoptera litura) di areal pertanaman. Serangan ulat ini tidak mengganggu pertumbuhan dan produksi tanaman. Pengendalian ulat ini dilakukan secara 
manual, yaitu dengan cara membunuh ulat tersebut.

Suhu greenhouse pada pagi hari berkisar antara $24.5-36^{\circ} \mathrm{C}$, siang hari $24-41.5^{\circ} \mathrm{C}$ dan sore hari $22-40^{\circ} \mathrm{C}$. RH greenhouse pada pagi hari sekitar 51-100\%, siang hari $41-98 \%$ dan sore hari $54-100 \%$. Suhu tertinggi terjadi pada siang hari sedangkan kelembaban udara relatif (RH) tertinggi terjadi pada sore hari. Suhu dan kelembaban relatif (RH) greenhouse mengalami fluktuasi selama penelitian. Intensitas cahaya di dalam greenhouse pada siang hari memiliki kisaran yang lebih tinggi (6200-34500 lux) dibandingkan pada pagi (2000-34000 lux) dan sore hari (800 -34600 lux).

Suhu larutan hara pada pagi hari untuk setiap perlakuan relatif sama yaitu sekitar $25-27^{\circ} \mathrm{C}$, siang hari $26-30^{\circ} \mathrm{C}$ dan pada sore hari $25-28^{\circ} \mathrm{C}$. Suhu larutan hara pada keempat perlakuan ketika siang hari cenderung mengalami peningkatan. Nilai EC larutan hara cenderung menurun dengan bertambahnya umur tanaman. Perlakuan EC 0.75 mS.cm ${ }^{-1}, 1.50 \mathrm{mS} . \mathrm{cm}^{-1}$ dan $2.25 \mathrm{mS} . \mathrm{cm}^{-1}$ memiliki kecenderungan nilai EC yang menurun selama penelitian (0.77 menjadi $0.76 \mathrm{mS} . \mathrm{cm}^{-1}$ pada perlakuan EC $0.75,1.55$ menjadi $1.44 \mathrm{mS} . \mathrm{cm}^{-1}$ pada perlakuan EC $1.50 \mathrm{mS} . \mathrm{cm}^{-1}$ dan 2.31 menjadi $2.18 \mathrm{mS} . \mathrm{cm}^{-1}$ pada perlakuan EC 2.25 $\mathrm{mS} . \mathrm{cm}^{-1}$ ), sedangkan nilai EC larutan kontrol memiliki kecenderungan meningkat dari 0.13 menjadi $0.20 \mathrm{mS} . \mathrm{cm}^{-1}$.

Nilai $\mathrm{pH}$ pada larutan kontrol berkisar antara 6.66

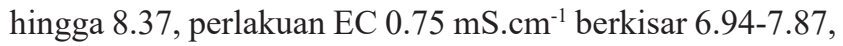
perlakuan EC $1.50 \mathrm{mS} . \mathrm{cm}^{-1}$ berkisar 6.45-7.50 dan perlakuan

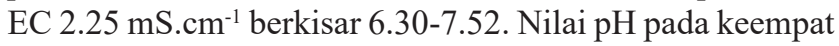
perlakuan larutan cenderung mengalami peningkatan. Nilai DO (Dissolved Oxygen/Oksigen Terlarut) pada semua perlakuan cenderung mengalami penurunan hingga akhir penelitian. Pada larutan kontrol, nilai DO menurun dari 2.76 menjadi 2.03, perlakuan EC 0.75 mS.cm ${ }^{-1}$ menurun dari 4.87 menjadi 1.93, perlakuan EC $1.50 \mathrm{mS} . \mathrm{cm}^{-1}$ menurun dari 3.95 menjadi 1.73 dan perlakuan EC $2.25 \mathrm{mS} . \mathrm{cm}^{-1}$ menurun dari 4.76 menjadi 1.44 .

\section{Pertumbuhan Tanaman}

Peningkatan konsentrasi hara sampai taraf 2.25 mS.cm ${ }^{-1}$ memberikan pengaruh yang nyata dalam menurunkan tinggi tanaman secara linier pada 1 MST dan memberikan efek kuadratik yang sangat nyata pada 2-4 MST (Tabel 1). Aplikasi konsentrasi larutan hara empat taraf ini berpengaruh nyata secara linear dalam menurunkan jumlah daun selada pada umur 1-2 MST, tetapi ketika umur 3-4 MST aplikasi tersebut berpengaruh sangat nyata secara kuadratik (Tabel 1).

\section{Diameter Batang dan Jumlah Tanaman Hidup per Panel}

Perlakuan konsentrasi larutan hara berpengaruh tidak nyata terhadap diameter batang selada umur 1-2 MST. Perlakuan memberikan efek kuadratik pada 3-4 MST (Tabel 1). Pengaruh konsentrasi larutan hara sampai pada taraf $2.25 \mathrm{mS} . \mathrm{cm}^{-1}$ tidak nyata terhadap jumlah tanaman hidup per panel (Tabel 2).

\section{Hasil Panen}

Aplikasi konsentrasi larutan hara sampai EC 2.25 $\mathrm{mS} . \mathrm{cm}^{-1}$ menunjukkan respon yang sangat nyata secara linier dalam menurunkan panjang akar dan berespon tidak nyata terhadap bobot akar selada. Perlakuan konsentrasi larutan hara berpengaruh sangat nyata secara kuadratik terhadap bobot total dan bobot marketable per panel (Tabel 2).

Berdasarkan persamaan garis yang terbentuk (Gambar 1), perlakuan konsentrasi larutan hara memberikan pengaruh yang sangat nyata secara kuadratik terhadap bobot total dan bobot yang dapat dipasarkan per tanaman (Tabel 2). Berdasarkan perhitungan matematis $\mathrm{y}=-6.7871 \mathrm{x}^{2}+15.013 \mathrm{x}$ +29.162 dengan $\mathrm{R}^{2}=0.1791$ pada bobot total didapatkan nilai EC optimum sebesar $1.11 \mathrm{mS} . \mathrm{cm}^{-1}$ dan $\mathrm{y}=-6.6675 \mathrm{x}^{2}$ $+15.362 \mathrm{x}+18.595$ dengan $\mathrm{R}^{2}=0.1942$ pada bobot yang dapat dipasarkan didapatkan nilai EC optimum sebesar 1.15 $\mathrm{mS} . \mathrm{cm}^{-1}$.

\section{Analisis Usaha Tani}

Analisis usaha tani ini dibuat berdasarkan konsentrasi larutan hara yang optimum (Data tidak secara lengkap ditampilkan). Berdasarkan hasil analisis ini, diperoleh keuntungan sekitar Rp. 1.109.210,- per musim tanam, dengan $\mathrm{B} / \mathrm{C}$ sebesar 0.48 dan $\mathrm{R} / \mathrm{C}$ sebesar 1.48 . Hal ini menunjukkan bahwa usaha ini cukup menguntungkan

Tabel 1. Respon pertumbuhan vegetatif tanaman akibat pengaruh konsentrasi larutan hara

\begin{tabular}{|c|c|c|c|c|c|c|c|c|c|c|c|c|}
\hline \multirow{2}{*}{ Perlakuan } & \multicolumn{4}{|c|}{ Tinggi tanaman $(\mathrm{cm})$} & \multicolumn{4}{|c|}{ Jumlah daun } & \multicolumn{4}{|c|}{ Diameter batang $(\mathrm{cm})$} \\
\hline & $1 \mathrm{MST}$ & $2 \mathrm{MST}$ & $3 \mathrm{MST}$ & $4 \mathrm{MST}$ & $1 \mathrm{MST}$ & $2 \mathrm{MST}$ & $3 \mathrm{MST}$ & $4 \mathrm{MST}$ & $1 \mathrm{MST}$ & $2 \mathrm{MST}$ & $3 \mathrm{MST}$ & $4 \mathrm{MST}$ \\
\hline \multicolumn{13}{|c|}{$\underline{\text { Konsentrasi Larutan }}$} \\
\hline Kontrol & 16.4 & 19 & 25.3 & 27.2 & 3.7 & 4.7 & 5.6 & 6.9 & 0.2 & 0.3 & 0.4 & 0.4 \\
\hline $0.75 \mathrm{mS} / \mathrm{cm}$ & 19.1 & 27 & 38.5 & 46.4 & 4.9 & 5.8 & 7.3 & 9.2 & 0.3 & 0.3 & 0.5 & 0.5 \\
\hline $1.50 \mathrm{mS} / \mathrm{cm}$ & 15.7 & 20.2 & 28.7 & 32.44 & 3.3 & 3.9 & 5 & 5.7 & 0.2 & 0.3 & 0.4 & 0.6 \\
\hline $2.25 \mathrm{mS} / \mathrm{cm}$ & 14.6 & 19.6 & 28.2 & 30.4 & 3.6 & 4.7 & 5.4 & 5.4 & 0.2 & 0.3 & 0.4 & 0.5 \\
\hline Respon & $\mathrm{L}^{*}$ & $\mathrm{Q}^{* *}$ & $\mathrm{Q}^{* *}$ & $\mathrm{Q}^{* *}$ & $\mathrm{~L}^{*}$ & $\mathrm{~L}^{*}$ & $\mathrm{Q}^{* *}$ & $\mathrm{Q}^{* *}$ & tn & tn & $\mathrm{Q}^{*}$ & $\mathrm{Q}^{* *}$ \\
\hline
\end{tabular}

Keterangan : tn : tidak berpengaruh nyata, * : berpengaruh nyata pada uji statistik $(\mathrm{p}<5 \%$ ), ** : berpengaruh sangat nyata pada uji statistik ( $<1 \%$ ), L : berpengaruh secara linear, $\mathrm{Q}$ : berpengaruh secara kuadratik 
sehingga memungkinkan konsentrasi larutan hara dengan EC $1.15 \mathrm{mS} . \mathrm{cm}^{-1}$ dapat dikembangkan lebih lanjut untuk budidaya sayuran secara THST.

\section{Analisis Kandungan Klorofil dan Kandungan Hara Selada}

Aplikasi konsentrasi larutan hara berpengaruh sangat nyata secara linear dalam meningkatkan kandungan klorofil (Tabel 3). Selain itu, kandungan N, P dan K cenderung mengalami peningkatan.

\section{Pembahasan}

Peningkatan nilai $\mathrm{pH}$ yang terjadi pada keempat perlakuan disebabkan tanaman menyerap anion $\left(\mathrm{NO}_{3}^{-}, \mathrm{PO}_{4}^{-}\right.$ dan $\left.\mathrm{SO}_{4}^{-}\right)$lebih cepat daripada kationnya $\left(\mathrm{Ca}^{+}, \mathrm{Mg}^{+}\right.$dan $\left.\mathrm{K}^{+}\right)$. Anion diganti oleh ion hidroksil $\left(\mathrm{OH}^{-}\right)$yang dilepaskan selsel tanaman atau ion bikarbonat $\left(\mathrm{HCO}_{3}^{-}\right)$yang dihasilkan oleh respirasi akar (Harjadi, 1989).

Penurunan nilai EC yang terjadi pada larutan hara perlakuan EC $0.75 \mathrm{mS} . \mathrm{cm}^{-1}, 1.50 \mathrm{mS} . \mathrm{cm}^{-1}$ dan 2.25 $\mathrm{mS} . \mathrm{cm}^{-1}$ dikarenakan adanya absorbsi ion-ion nutrisi oleh akar tanaman. Perubahan yang terjadi di dalam larutan nutrisi dikarenakan tanaman mengabsorbsi berbagai elemen nutrisi yang terdapat di dalam larutan (Resh, 1998). Susila dan Koerniawati (2004) mengatakan bahwa nilai TDS cenderung semakin menurun dengan bertambahnya umur tanaman karena terjadi penyerapan unsur hara. Nilai oksigen terlarut (Dissolved Oxygen-DO) yang terjadi pada keempat perlakuan cenderung mengalami penurunan. Hal ini disebabkan oksigen terlarut yang terdapat pada larutan hara digunakan akar tanaman untuk respirasi aerobik, yang kemudian melepaskan energi untuk pertumbuhan akar (Morgan, 2000).

Semakin tinggi konsentrasi larutan hara maka semakin pendek akar tanaman yang tumbuh. Hasil penelitian Putri (2004) menunjukkan bahwa semakin miskin larutan hara maka akar tanaman kangkung akan semakin memanjang. Lambers et al. (1996) mengatakan bahwa tanaman yang hidup pada lingkungan dengan suplai hara yang

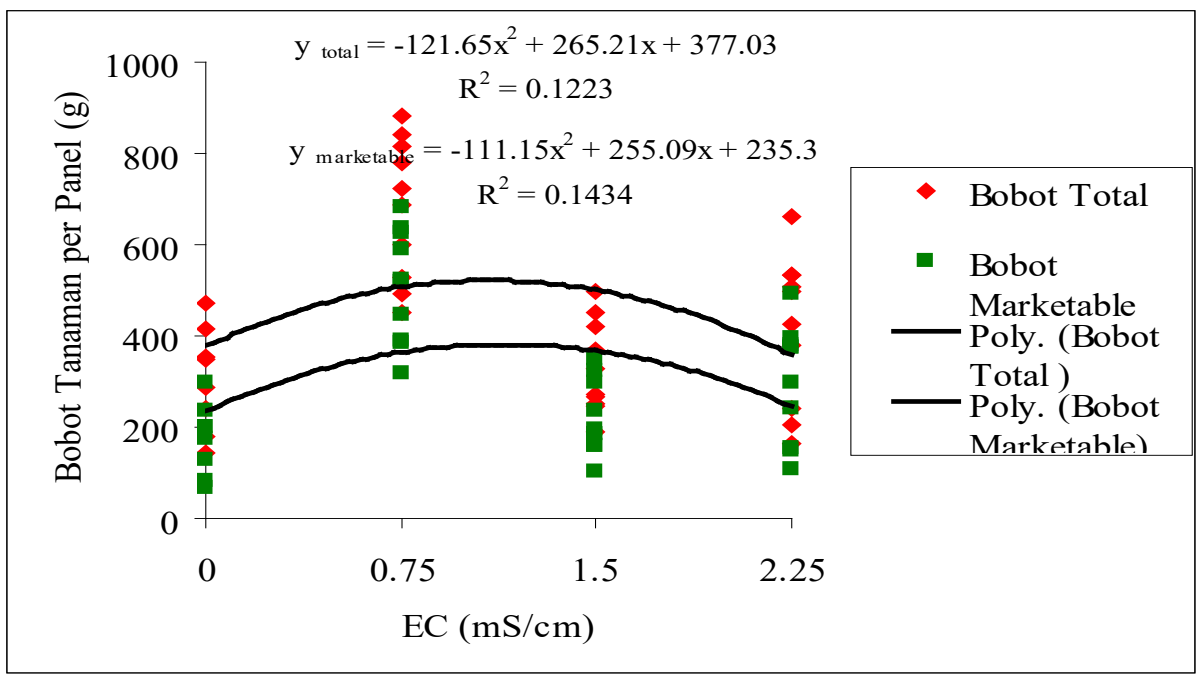

Gambar 1. Respon bobot tanaman per panel terhadap konsentrasi larutan hara

Tabel 2. Respon komponen hasil akibat pengaruh konsentrasi larutan hara

\begin{tabular}{|c|c|c|c|c|c|c|c|}
\hline \multirow{2}{*}{ Perlakuan } & \multirow{2}{*}{$\begin{array}{c}\text { Jumlah } \\
\text { tanaman hidup }\end{array}$} & \multirow{2}{*}{$\begin{array}{l}\text { Panjang akar } \\
\text { tanaman }(\mathrm{cm})\end{array}$} & \multirow{2}{*}{$\begin{array}{l}\text { Bobot akar } \\
\operatorname{tanaman}(\mathrm{g})\end{array}$} & \multicolumn{2}{|c|}{ Bobot tanaman per panel $(\mathrm{g})$} & \multicolumn{2}{|c|}{ Bobot per tanaman $(\mathrm{g})$} \\
\hline & & & & Bobot total & $\begin{array}{c}\text { Bobot } \\
\text { marketable }\end{array}$ & Bobot total & $\begin{array}{c}\text { Bobot } \\
\text { marketable }\end{array}$ \\
\hline \multicolumn{8}{|c|}{ Konsentrasi Larutan } \\
\hline Kontrol & 12.4 & 18.7 & 10.236 & 305.4 & 173.6 & 26 & 13.6 \\
\hline $0.75 \mathrm{mS} / \mathrm{cm}$ & 13.8 & 11 & 11.031 & 679.4 & 512.1 & 44.1 & 36.7 \\
\hline $1.50 \mathrm{mS} / \mathrm{cm}$ & 11.4 & 11.4 & 8.981 & 329.2 & 219.8 & 28.9 & 19 \\
\hline $2.25 \mathrm{mS} / \mathrm{cm}$ & 12.7 & 9.4 & 9.44 & 415.2 & 295.9 & 31.1 & 22.4 \\
\hline Respon & tn & $\mathrm{L} * *$ & tn & $\mathrm{Q}^{* *}$ & $\mathrm{Q}^{* *}$ & $\mathrm{Q}^{* *}$ & $\mathrm{Q}^{* *}$ \\
\hline
\end{tabular}

Keterangan : tn : tidak berpengaruh nyata, $* *$ : berpengaruh sangat nyata pada uji statistik $(\mathrm{p}<1 \%), \mathrm{L}$ : berpengaruh secara linear, Q : berpengaruh secara kuadratik 
sangat terbatas, $10-50 \%$ karbohidrat yang dihasilkan dari fotosintesis setiap harinya digunakan untuk respirasi akar. Menurut Morgan (2000) sistem akar tanaman memerlukan oksigen untuk respirasi aerobik, yang melepaskan energi yang diperlukan untuk pertumbuhan akar. Pada larutan kontrol, kadar oksigen terlarut yang dimilikinya cenderung paling tinggi dibandingkan ketiga perlakuan lainnya. Hal ini diduga juga merupakan penyebab dari panjangnya akar yang dimiliki tanaman kontrol karena dengan kadar oksigen yang lebih tinggi ini energi respirasi akar lebih dominan dialokasikan untuk pertumbuhan akar sehingga dengan pertumbuhan akar yang cukup pesat, air dan hara yang dapat diserap dari larutan yang miskin hara ini lebih banyak.

Berdasarkan titik optimum pada bobot total dan bobot marketable baik per panel maupun per tanaman, maka rekomendasi konsentrasi larutan hara optimum pada budidaya selada dengan THST berada pada kisaran EC 1.09-1.15 mS.cm ${ }^{-1}$. Pada kisaran ini, produksi selada yang diperoleh mencapai 521.139-521.576 gram per panel atau 109.44-109.53 kg per kolam $\left(51 \mathrm{~m}^{2}\right)$ tiap empat minggu dan dalam jangka waktu satu tahun akan menghasilkan produksi sekitar 1.3 ton selada per $51 \mathrm{~m}^{2}$.

Tabel 3. Kandungan klorofil dan kandungan hara selada umur 8 MST

\begin{tabular}{|c|c|c|c|c|}
\hline \multirow[t]{2}{*}{ Perlakuan } & \multirow{2}{*}{$\begin{array}{c}\text { Kandungan } \\
\text { Klorofil } \\
(\%)\end{array}$} & \multicolumn{3}{|c|}{$\begin{array}{c}\text { Kandungan Hara } \\
\text { Tajuk Tanaman } \\
(\% \text { bobot kering })\end{array}$} \\
\hline & & $\mathrm{N}$ & $\mathrm{P}$ & $\mathrm{K}$ \\
\hline \multicolumn{5}{|c|}{ Konsentrasi Larutan Hara } \\
\hline Kontrol & 0.051 & 1.78 & 0.36 & 2.45 \\
\hline $0.75 \mathrm{mS} / \mathrm{cm}$ & 0.054 & 1.64 & 0.4 & 2.2 \\
\hline $1.50 \mathrm{mS} / \mathrm{cm}$ & 0.060 & 1.83 & 0.46 & 3 \\
\hline $2.25 \mathrm{mS} / \mathrm{cm}$ & 0.052 & 3.18 & 0.5 & 5.5 \\
\hline Respon & $\mathrm{L} * *$ & & & \\
\hline
\end{tabular}

Keterangan: $\mathrm{L}$ : berpengaruh secara linear, $* *$ : berpengaruh sangat nyata pada uji statistik $(\mathrm{p}<1 \%)$

\section{KESIMPULAN}

1. Perlakuan konsentrasi larutan hara sampai dengan taraf EC $2.25 \mathrm{mS} . \mathrm{cm}^{-1}$ secara umum mempengaruhi tinggi tanaman, jumlah daun, diameter batang, bobot tanaman per panel dan bobot per tanaman secara kuadratik.

2. Rekomendasi konsentrasi larutan hara yang optimum untuk pertumbuhan dan produksi selada THST adalah $1.09-1.15 \mathrm{mS} . \mathrm{cm}^{-1}$.

\section{DAFTAR PUSTAKA}

Harjadi, S.S. 1989. Dasar Hortikultura. IPB. Bogor. 506 hal.

Lambers, H., I. Stulen, A. van der Werf. 1996. Carbon use in root respiration as affected by elevated atmospheric $\mathrm{O}_{2}$. Plant and Soil 187:251-263.

Morgan, L. 2000. Are your plants suffocating? The importance of oxygen in hydroponics. The Growing Edge 12(6):50-54.

Nurfinayati. 2004. Pemanfaatan Berulang Larutan Nutrisi pada Budidaya Selada (Lactuca sativa 1.) dengan Teknologi Hidroponik Sistem Terapung (THST). Skripsi. Departemen Budidaya Pertanian. Institut Pertanian Bogor. Bogor.

Putri, U.T. 2004. Penggunaan kembali (re-use) larutan hara pada teknologi hidroponik sistem terapung beberapa komoditas sayuran daun. Skripsi. Departemen Budidaya Pertanian, Institut Pertanian Bogor. Bogor.

Resh, H.M. 1998. Hydroponic Food Production. Woodbridge Press Publ. Santa Barbara. 527 p.

Roan, P.N.M. 1998. Pengaruh Aerasi dan Bahan Pemegang Tanaman pada Tiga Tahap Konsentrasi Terhadap Pertumbuhan Selada (Lactuca sativa L.) dalam Sistem Hidroponik Mengapung. Skripsi. Jurusan Budidaya Pertanian. Institut Pertanian Bogor. Bogor.

Rubatzky, V.E., M. Yamaguchi. 1998. Sayuran Dunia: Prinsip, Produksi dan Gizi. Jilid kedua. Diterjemahkan oleh C. Herikson. Institut Teknologi Bandung. Bandung. 292 hal.

Susila, A., Y. Koerniawati. 2004. Pengaruh volume dan jenis media tanam pada pertumbuhan dan hasil tanaman selada (Lactuca sativa) dalam teknologi hidroponik sistem terapung. Bul. Agron. 32(3):16-21. 